\title{
A novel model-based approach for dose determination of glycopyrronium bromide in COPD
}

Helen Arievich ${ }^{1}$, Tim Overend $^{2 *}$, Didier Renard ${ }^{3}$, Michael Gibbs², Vijay Alagappan², Michael Looby ${ }^{3}$ and Donald Banerji ${ }^{4}$

\begin{abstract}
Background: Glycopyrronium bromide (NVA237) is an inhaled long-acting muscarinic antagonist in development for treatment of COPD. This study compared the efficacy and safety of once-daily (OD) and twice-daily (BID) glycopyrronium bromide regimens, using a novel model-based approach, in patients with moderate-to-severe COPD.

Methods: Double-blind, randomized, dose-finding trial with an eight-treatment, two-period, balanced incomplete block design. Patients (smoking history $\geq 10$ pack-years, post-bronchodilator $\mathrm{FEV}_{1} \geq 30 \%$ and $<80 \%$ predicted, $\mathrm{FEV}_{1} /$ FVC <0.7) were randomized to one of 16 independent sequences for 28 days. Primary endpoint: mean trough FEV 1 at Day 28.
\end{abstract}

Results: 385 patients (mean age 61.2 years; mean post-bronchodilator $\mathrm{FEV}_{1} 53 \%$ predicted) were randomized; $88.6 \%$ completed. All OD and BID dosing regimens produced dose-dependent bronchodilation; at Day 28, increases in mean trough $\mathrm{FEV}_{1}$ versus placebo were statistically significant for all regimens, ranging from $51 \mathrm{~mL}$

(glycopyrronium bromide $12.5 \mu \mathrm{g}$ OD) to $160 \mathrm{~mL}$ (glycopyrronium bromide $50 \mu \mathrm{g} \mathrm{BID).} \mathrm{Pharmacodynamic}$ steady-state was reached by Day 7 . There was a small separation $(\leq 37 \mathrm{~mL})$ between BID and OD dose-response curves for mean trough $\mathrm{FEV}_{1}$ at steady-state in favour of BID dosing. Over 24 hours, separation between OD and $\mathrm{BID}$ regimens was even smaller ( $F E V_{1} \mathrm{AUC}_{0-24 \mathrm{~h}}$ maximum difference for equivalent daily dose regimens: $8 \mathrm{~mL}$ ). Dose-response results for $\mathrm{FEV}_{1}$ at 12 hours, $F E V_{1} \mathrm{AUC}_{0-12 \mathrm{~h}}$ and $\mathrm{FEV}_{1} \mathrm{AUC}_{0-4 \mathrm{~h}}$ at steady-state showed OD regimens provided greater improvement over placebo than BID regimens for total daily doses of $25 \mu \mathrm{g}, 50 \mu \mathrm{g}$ and $100 \mu \mathrm{g}$, while the reverse was true for OD versus BID regimens from 12-24 hours. The $12.5 \mu \mathrm{g}$ BID dose produced a marginally higher improvement in trough $\mathrm{FEV}_{1}$ versus placebo than $50 \mu \mathrm{gD}$, however, the response at 12 hours over placebo was suboptimal (74 mL). Glycopyrronium bromide was safe and well tolerated at all doses.

Conclusions: Glycopyrronium bromide $50 \mu \mathrm{g}$ OD provides significant bronchodilation over a 24 hour period, and in terms of $\mathrm{FEV}_{1} \mathrm{AUC}_{0-24 \mathrm{~h}}$ is not significantly different than the same total daily dose administered BID. Importantly, OD dosing may confer better patient adherence. The results are consistent with previous glycopyrronium bromide studies and support once-daily dosing of glycopyrronium bromide $50 \mu \mathrm{g}$ in patients with moderate-to-severe COPD.

Trial registration: ClinicalTrials.gov: NCT01119950

Keywords: Glycopyrronium bromide (NVA237), Once-daily, Twice-daily, COPD, Dose-response, LAMA, Adherence

\footnotetext{
* Correspondence: tim.overend@novartis.com

${ }^{2}$ Novartis Horsham Research Centre, Wimblehurst Road, Horsham, West Sussex RH12 5AB, UK

Full list of author information is available at the end of the article
}

\section{Biomed Central}

(c) 2012 Arievich et al.; licensee BioMed Central Ltd. This is an Open Access article distributed under the terms of the Creative Commons Attribution License (http://creativecommons.org/licenses/by/2.0), which permits unrestricted use, distribution, and reproduction in any medium, provided the original work is properly cited. 


\section{Background}

Chronic obstructive pulmonary disease (COPD) is characterized by progressive airflow obstruction, resulting in airflow limitation that is only partially reversible $[1,2]$. COPD is a major cause of morbidity and mortality worldwide, and represents a substantial economic and social burden that is expected to increase [1].

Bronchodilators are the cornerstone treatment for all COPD severity stages. Long-acting muscarinic antagonists (LAMAs) are one of the main classes of bronchodilators used for the treatment of COPD. The optimal characteristics of a LAMA for use in COPD would be to provide the following: clinically meaningful bronchodilation, in addition to symptom relief, prevention of disease progression, improvement in exercise tolerance and health status, prevention and treatment of complications and exacerbations and a reduction in mortality risk $[1,3,4]$. Other characteristics of an ideal LAMA would include strong selectivity for muscarinic type 3 (M3) receptors, long duration of action, rapid onset of action, and a good safety and tolerability profile [1,4].

NVA237 is a dry-powder formulation of glycopyrronium bromide. As with other LAMAs, its bronchodilatory effects result from blockade of muscarinic type 1 (M1) and $\mathrm{M} 3$ receptors, which are involved in either transmission of nerve impulses or promotion of contraction in airway smooth muscle. Glycopyrronium bromide has a low oral bioavailability, is selective for M3 over muscarinic type 2 (M2) receptors, and equilibrates rapidly with M3 receptors [4]. Dosages of $50 \mu \mathrm{g}$ and $100 \mu \mathrm{g}$ once daily (OD) have been identified in a phase II trial as providing effective bronchodilation, with clinically meaningful improvements in forced expiratory volume in 1 second $\left(\mathrm{FEV}_{1}\right)$ over 7 days' treatment. Compared with open-label tiotropium $18 \mu \mathrm{g}$ OD, glycopyrronium bromide $50 \mu \mathrm{g}$ OD appears similar in terms of bronchodilatory efficacy and duration of action, although the latter has a more rapid onset of action $[5,6]$. Post-hoc analysis has also confirmed superior bronchodilation and responder rates with glycopyrronium bromide $50 \mu \mathrm{g}$, compared with lower doses (12.5 and $25 \mu \mathrm{g})$, while tolerability profiles were similar across the dose range [7]. The efficacy of glycopyrronium bromide $50 \mu \mathrm{g}$ OD has been confirmed in a further study, showing it to provide sustained 24-hour bronchodilation during 14 days' treatment [8]. In these studies, glycopyrronium bromide was well tolerated, even at dosages as high as $200 \mu \mathrm{g}$ OD (4 times the dosage identified as the lowest dose producing clinically significant improvements in bronchodilation) [9]. Based on the results of these earlier efficacy and safety studies, a dose of $50 \mu \mathrm{g}$ OD was selected for further clinical evaluation in Phase III trials.

The present study in patients with stable COPD aimed to evaluate the efficacy and safety of twice-daily (BID) dosing regimens for glycopyrronium bromide, versus the same total daily dose administered on an OD basis, by fully characterizing the dose-response relationship of both regimens. The doses evaluated ranged from $12.5 \mu \mathrm{g}$ OD to $50 \mu \mathrm{g}$ BID. Standard statistical methods routinely applied in bronchodilator studies, such as analysis of covariance, are intended to allow direct pairwise comparisons. However, these methods are not suitable for detailed dose-response characterization because they only provide information on each comparison independently and not on the dose-response relationship as a whole. Given the number of pairwise comparisons necessary to piecewise reconstruct a dose-response relationship with reasonable resolution, none of the pairwise comparisons will have adequate precision to allow differentiation across the doses due to sample size limitations. This fundamental limitation in dose-response assessment for spirometric measures has been discussed previously $[10,11]$. For these reasons, a rigorous pre-specified model-based approach was used to allow definitive estimation of the dose-response and dose-regimen relationships. This relationship, in turn, was used as the basis for dose differentiation.

\section{Methods}

This study was conducted between April and December 2010 at 50 centres in 9 countries (Belgium, Germany, Hungary, India, The Netherlands, Poland, Romania, Spain and USA). The study was performed according to the ethical principles of the Declaration of Helsinki; the protocol was reviewed by the Independent Ethics Committee or Institutional Review Board for each participating centre. All patients provided written informed consent before enrolling in the study (Additional file 1: Appendix 1).

\section{Patients}

Included in this study were male and female adults aged $\geq 40$ years with stable moderate-to-severe COPD [12] and a smoking history of $\geq 10$ pack-years (defined as: 20 cigarettes/day for 10 years, or 10 cigarettes/day for 20 years, etc.). Patients were required to have a postbronchodilator (45 min after inhalation of $84 \mu \mathrm{g}$ ipratropium bromide) $\mathrm{FEV}_{1} \geq 30 \%$ and $<80 \%$ of the predicted normal, and post-bronchodilator $\mathrm{FEV}_{1}$ to forced vital capacity (FVC) ratio $<0.7$ at screening. Patients must also have been symptomatic, according to daily electronic diary data collected during a 1-week run-in period, with a total score $\geq 1$ on at least 4 of the 7 days prior to Day 1 of the study.

Study exclusion criteria included: hospitalization for exacerbation of airways disease in the 6 weeks prior to study start, respiratory tract infection within 4 weeks prior to study start, prolonged QTc interval at screening (or history of long QT syndrome), requiring daily oxygen therapy for chronic hypoxemia, history of asthma, Type 
1 or uncontrolled Type 2 diabetes, history of malignancy in the previous 5 years (except localized basal cell carcinoma of the skin), or any other clinically relevant medical condition or laboratory abnormality that might have compromised safety or compliance. Also excluded were those with history of an untoward reaction to any of the study drugs, women of child-bearing potential not using an accepted form of contraception, pregnant women, and nursing mothers.

Use of inhaled salbutamol/albuterol as rescue medication was permitted throughout the study (except immediately before and during study visits, unless absolutely necessary). Patients taking fixed combinations of inhaled corticosteroids (ICS) and long-acting $\beta_{2}$-agonists (LABA) were transferred to the nearest equivalent ICS monotherapy at least 48 hours prior to screening. Use of the following medications was not permitted during this study: long-acting anticholinergics (minimum washout period prior to screening: 7 days), short-acting anticholinergics (8 h), LABAs (48 h), short-acting $\beta_{2}$-agonists other than rescue medication $(6 \mathrm{~h})$, fixed combinations of inhaled short-acting anticholinergics and short-acting $\beta_{2}$-agonists $(8 \mathrm{~h})$, xanthines (7 days), parenteral or oral corticosteroids (1 month), and intramuscular depot corticosteroids (3 months). Also prohibited were: any drugs with potential to significantly prolong the QT interval (e.g. mizolastin; minimum washout prior to screening: 14 days or 5 half-lives, whichever was longer), other investigational drugs (30 days or 5 half-lives, whichever was longer), non-selective beta-blockers (7 days), leukotriene antagonists (7 days), cromoglycate (7 days), Nedocromil (7 days), Ketotifen (7 days), systemic anticholinergics (7 days). Patients who had live attenuated vaccinations within 30 days prior to the screening visit or during the run-in period were excluded from taking part in the study (inactivated influenza vaccination, pneumococcal vaccination or any other inactivated vaccine was acceptable provided it was administered $\geq 48$ hours prior to the screening and/or randomization visit).

\section{Study design}

This was a double-blind, randomized, dose-finding trial utilizing an eight-treatment, two-period, balanced incomplete block design. Patients were randomized to one of 16 independent sequences and received two treatments from: glycopyrronium bromide $12.5 \mu \mathrm{g}$ OD, $12.5 \mu \mathrm{g}$ BID, $25 \mu \mathrm{g}$ OD, $25 \mu \mathrm{g}$ BID, $50 \mu \mathrm{g}$ OD, $50 \mu \mathrm{g}$ BID, $100 \mu \mathrm{g}$ OD, or placebo in a 1:1:1:1:1:1:1:1 ratio, with balanced representation of each treatment. Patients received study drug for 28 days in the first treatment period, then entered a 7-day washout period, during which they continued only with their background COPD medication, before commencing the second 28-day treatment period. All short-acting COPD medications were thoroughly washed out prior to commencing the second treatment period. Patients received their first dose of study medication in the clinic between 08:00 and 10:00 in the morning. Patients were instructed to take study medication every day at home between 08:00 and 10:00 in the morning, and the evening dose 12 hours later $( \pm 15 \mathrm{~min})$, between 20:00 (8 pm) and 22:00 (10 pm). For patients on OD regimens, active treatment was administered in the morning and placebo in the evening, to maintain blinding of OD versus BID regimens. Patients were required to attend the study centres for 18 visits.

\section{Study assessments and variables}

Efficacy assessments were based on centralized spirometry (using standardized spirometry equipment with review of data by qualified personnel at a Contract Research Organization) $\mathrm{FEV}_{1}$ and FVC were measured on Days 1, 7 and 14 at the following timepoints relative to the morning dose: 45 and 15 minutes pre-dose and 5 minutes and 1, 2, 4, 8, 10 hours, 11 hours 55 minutes, and 14 hours post dose, with assessments continuing the following day at 20 and 22 hours, 23 hours 15 minutes and 23 hours 45 minutes post dose. Day 28 spirometry tests followed the same schedule, with additional assessments at 15 minutes and 3 and 6 hours post dose.

The primary efficacy variable was trough $\mathrm{FEV}_{1}$ at Day 28 (defined as the mean of the $23 \mathrm{~h} 15 \mathrm{~min}$ and $23 \mathrm{~h}$ $45 \mathrm{~min}$ post-dose values). Secondary efficacy variables included $\mathrm{FEV}_{1}$ area under the curve for time 0-24 hours post dose $\left(\mathrm{AUC}_{0-24 \mathrm{~h}} \mathrm{FEV}_{1}\right), \mathrm{FEV}_{1} \mathrm{AUC}_{0-4 \mathrm{~h}}, \mathrm{FEV}_{1} \mathrm{AUC}_{0-12 \mathrm{~h}}$, $\mathrm{FEV}_{1} \mathrm{AUC}_{12-24 \mathrm{~h}}, \mathrm{FEV}_{1}$ at 12 hours and peak $\mathrm{FEV}_{1}$, all measured after 28 days of treatment. The AUC measures were standardized by the length of time interval.

Safety assessments consisted of collecting adverse events (AEs; including their severity and possible relationship to study drug) and pregnancies, assessing vital signs, and electrocardiogram (ECG) throughout the study. Haematology, blood chemistry and urinalysis parameters were assessed at screening and at the final dosing visit in each treatment period. An independent adjudication committee was used to classify deaths during the study.

\section{Statistical analyses}

A non-linear dose-response modelling approach was used to evaluate the bronchodilator efficacy of doses administered either OD or BID after 28 days of treatment (Additional file 2: Appendix 2). Based on previous glycopyrronium bromide spirometric results [5], the shape of the dose-response curve was assumed to be of $\mathrm{E}_{\text {max }}$-type:

$$
\frac{E_{\max } \times \operatorname{dose}^{\gamma}}{\left(E D_{50} / \theta^{I(\mathrm{BID})}\right)^{\gamma}+\operatorname{dose}^{\gamma}}
$$

where dose represents total daily dose, $E_{0}$ is the placebo effect, $E_{\max }=$ the maximum (placebo-adjusted) drug effect, $\mathrm{ED}_{50}=\mathrm{a}$ measure of drug potency interpreted as the dose 
providing $50 \%$ of the maximum effect and $\gamma$ is a steepness parameter. Further assumptions were that regimen acts as a potency $\left(\mathrm{ED}_{50}\right)$ modifier and that a common maximal effect $\left(E_{\max }\right)$ is reached for both regimens. A sensitivity analysis of trough $\mathrm{FEV}_{1}$, performed relaxing the latter assumption, provided similar results.

For each spirometry outcome, the actual analysis used data collected over the entire course of treatment (Days $1,7,14$ and 28). To reduce potential bias, eight candidate models were selected to characterize the bronchodilatory dose response over time and were prospectively specified. Half of the models had a fixed value $\gamma=1$ in the above equation; the other half allowed estimating the $\gamma$ parameter. For each set of four models, the longitudinal component either assumed a smooth increase in $\mathrm{FEV}_{1}$ response from Day 1 to Day 28, or a flat response at Day 7 onwards. Each model included random terms to represent inter-individual (patient), inter-occasion (patient-period) and residual variability, all assumed to be normally distributed. Each model was further adjusted using the SAS procedure NLMIXED with the first-order method (method = FIRO) for: period baseline $\mathrm{FEV}_{1}$ measurement; $\mathrm{FEV}_{1}$ prior to inhalation and $\mathrm{FEV}_{1}$ 45 minutes post inhalation of ipratropium bromide (components of reversibility at Day 14); smoking status (current/ex-smoker); baseline ICS use (yes/no); and period (fixed effect).

Each of the candidate models that were successfully fitted provided an estimate of dose response at Day 28. The final characterization of dose response relied on model averaging, i.e. a weighted average of the different models. Weights for each model were a function of the Bayesian information criterion (BIC), i.e. models that best represented the data carried a greater weight in the estimate. Confidence limits around model-average estimates were obtained using a simulation-based procedure.

Results were expressed as percentages of the maximal placebo-adjusted effect of glycopyrronium bromide $\left(\mathrm{E}_{\max }\right)$ and treatment differences were summarized for OD and BID regimens that provided the same total daily dose. No formal hypothesis testing was performed for this study; however, 90\% confidence intervals (CIs) are presented for selected analyses.

In order to characterize bronchodilation over the course of the whole day at steady-state, dose-response modelling was applied to the measured $\mathrm{FEV}_{1}$ for each spirometry timepoint separately (using the model assuming a flat dose response at Day 7 onwards and $\gamma=1$ ) and the results plotted to show the 24-hour profile.

The modified intent-to-treat (ITT) population included all those patients randomized who received at least one dose of study medication. These were used in the analysis of all efficacy variables. The safety population, used in the analysis of all safety variables, included all those patients who received at least one dose of study medication, including those who may have received it in error (this was identical to modified ITT population except for allowing for erroneous drug administration). Safety variables were analyzed descriptively, with clinically relevant or notable changes assessed. QTc interval was calculated using Fridericia's formula: QTc $=\mathrm{QT} / \sqrt[3]{\mathrm{RR}}$.

Assuming an overall dropout rate of $17 \%$, a planned sample size of 360 patients was considered sufficient to show that the upper limit of the 90\% CI (one-sided) for the maximum BID-OD difference in trough response falls below $40 \mathrm{~mL}$ with $80 \%$ chance, when the relative potency of BID versus OD regimens was assumed to be $120 \%$.

\section{Results}

\section{Patients}

A total of 385 patients were randomized and received study medication, with 341 (88.6\% of the modified ITT population) completing the study, providing evaluable data for 87-96 patients per treatment group. Baseline demographic and clinical characteristics are shown in Table 1. The mean age of patients in the study was 61.2 years (range 40-81 years, with the majority of patients being $<65$ years of age), $65.0 \%$ were male; and the mean duration of COPD was 7.7 years. Mean postbronchodilator $\mathrm{FEV}_{1}$ was $53 \%$ predicted.

\section{Efficacy}

\section{Primary endpoint: mean trough $\mathrm{FEV}_{1}$ at Day 28}

Glycopyrronium bromide reached pharmacodynamic steady-state by Day 7. At Day 28, all once daily and twice daily dosing regimens produced dose-dependent bronchodilation (Figure 1). Furthermore, all glycopyrronium bromide treatment groups had statistically significant absolute increases in mean trough $\mathrm{FEV}_{1}$ compared with placebo. Increases in $\mathrm{FEV}_{1}$ over that seen with placebo ranged from $51 \mathrm{~mL}$ (with glycopyrronium bromide $12.5 \mu \mathrm{g}$ OD) to $160 \mathrm{~mL}$ (with glycopyrronium bromide $50 \mu \mathrm{g}$ BID), equating to $27-85 \%$ of the model-predicted maximum effect of any glycopyrronium bromide dose (Table 2). For the primary efficacy variable of mean trough $\mathrm{FEV}_{1}$, separation between dose-response curves for OD and BID dosing regimens was observed although the difference was small, with an estimated difference of approximately $35 \mathrm{~mL}$, favouring BID, for total daily doses in the range of 25-50 $\mu$ g (Figure 1).

\section{Secondary endpoint: FEV 1 AUC at Day 28}

When $\mathrm{FEV}_{1}$ over the whole 24-hour period postmorning dose was considered, the separation was substantially reduced, with OD and BID regimens showing similar dose-response profiles for $\mathrm{FEV}_{1} \mathrm{AUC}_{0-24 \mathrm{~h}}$ for equivalent total daily doses (Figure 2). The estimated 
Table 1 Baseline demographics and clinical characteristics (safety population)

\begin{tabular}{|c|c|c|c|c|c|c|c|c|}
\hline & $\begin{array}{l}\text { Glycopyrronium } \\
\text { bromide } 12.5 \mu \mathrm{g} \\
\text { OD }(n=89)\end{array}$ & $\begin{array}{l}\text { Glycopyrronium } \\
\text { bromide } 25 \mu \mathrm{g} \\
\text { OD }(\mathrm{n}=96)\end{array}$ & $\begin{array}{l}\text { Glycopyrronium } \\
\text { bromide } 12.5 \mu \mathrm{g} \\
\text { BID }(n=96)\end{array}$ & $\begin{array}{l}\text { Glycopyrronium } \\
\text { bromide } 50 \mu \mathrm{g} \\
\text { OD }(\mathrm{n}=92)\end{array}$ & $\begin{array}{l}\text { Glycopyrronium } \\
\text { bromide } 25 \mu \mathrm{g} \text { BID } \\
(\mathrm{n}=96)\end{array}$ & $\begin{array}{l}\text { Glycopyrronium } \\
\text { bromide } 100 \mu \mathrm{g} \text { OD } \\
(\mathrm{n}=96)\end{array}$ & $\begin{array}{l}\text { Glycopyrronium } \\
\text { bromide } 50 \mu \mathrm{g} \\
\text { BID }(\mathrm{n}=87)\end{array}$ & $\begin{array}{l}\text { Placebo } \\
(n=91)\end{array}$ \\
\hline Age (years), mean (SD) & $60.2(7.77)$ & $60.0(7.98)$ & $60.9(7.89)$ & $59.2(8.14)$ & $61.2(7.80)$ & $62.1(7.83)$ & $62.2(7.74)$ & $63.2(7.67)$ \\
\hline Range & $47-79$ & $43-81$ & $40-80$ & $43-80$ & $40-80$ & $40-79$ & $49-81$ & $48-78$ \\
\hline \multicolumn{9}{|l|}{ Sex, n (\%) } \\
\hline Male & $56(62.9)$ & $64(66.7)$ & $67(69.8)$ & $56(60.9)$ & $66(68.8)$ & $59(61.5)$ & $59(67.8)$ & $56(61.5)$ \\
\hline \multicolumn{9}{|l|}{ Smoking history, n (\%) } \\
\hline Ex-smoker & $45(50.6)$ & $51(52.1)$ & $50(52.1)$ & $45(48.9)$ & $50(52.1)$ & $57(59.4)$ & $48(55.2)$ & $52(57.1)$ \\
\hline Current smoker & $44(49.4)$ & $45(46.9)$ & $46(47.9)$ & $47(51.1)$ & $46(47.9)$ & $39(40.6)$ & $39(44.8)$ & $39(42.9)$ \\
\hline Pack-years, mean (SD) & $43.2(23.05)$ & $39.6(19.97)$ & $40.9(19.88)$ & $39.3(19.91)$ & $42.8(23.26)$ & $39.8(19.79)$ & $42.1(21.17)$ & $40.4(20.84)$ \\
\hline \multicolumn{9}{|c|}{ FEV 1 pre-bronchodilator (\% predicted), n (\%) } \\
\hline & $47(12)$ & $46(11)$ & $46(14)$ & $46(11)$ & $45(12)$ & $46(14)$ & $48(13)$ & $48(13)$ \\
\hline \multicolumn{9}{|c|}{ FEV 1 post-bronchodilator (\% predicted), n (\%) } \\
\hline $30-<50 \%$ & $34(38.2)$ & $36(37.5)$ & $44(45.8)$ & $34(37.0)$ & $43(44.8)$ & $44(45.8)$ & $34(39.1)$ & $37(40.7)$ \\
\hline $50-<80 \%$ & $55(61.8)$ & $60(62.5)$ & $52(54.2)$ & $58(63.0)$ & $53(55.2)$ & $52(54.2)$ & $53(60.9)$ & $54(59.3)$ \\
\hline \multicolumn{9}{|l|}{$\mathrm{FEV}_{1}$ reversibility, $\%$} \\
\hline Mean (SD) & $17(12)$ & $19(16)$ & $16(14)$ & $17(12)$ & $16(12)$ & $17(18)$ & $16(16)$ & $16(16)$ \\
\hline Median (range) & $16(-11-44)$ & $19(-16-90)$ & $16(-43-55)$ & $18(-18-40)$ & $15(-13-44)$ & $16(-43-72)$ & $14(-21-90)$ & $13(-21-72)$ \\
\hline \multicolumn{9}{|c|}{$\mathrm{FEV}_{1} / \mathrm{FVC}(\%)$ post-bronchodilator (\%), mean (SD) } \\
\hline & $46.87(10.36)$ & $46.76(8.66)$ & $45.86(11.12)$ & 46.41 (9.29) & $46.15(10.21)$ & $47.21(11.72)$ & $47.89(9.57)$ & $48.22(10.65)$ \\
\hline
\end{tabular}

OD: once daily; BID: twice daily; SD: standard deviation; $\mathrm{FEV}_{1}$ : forced expiratory volume in one second; FVC: forced vital capacity. 


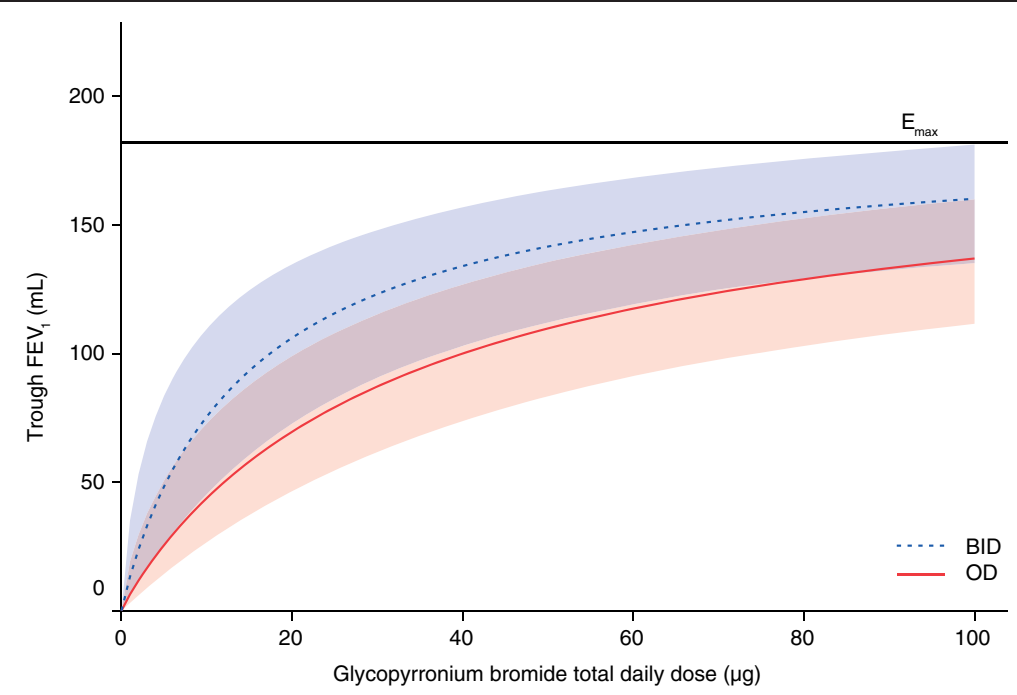

Figure 1 Trough $\mathrm{FEV}_{1}$ dose-response results at $\mathbf{2 4}$ hours at steady-state (modified intent-to-treat population). Model average placeboadjusted values for OD and BID dosing regimens, with $90 \%$ confidence limits (red and blue shaded areas, respectively). FEV ${ }_{1}$ : forced expiratory volume in one second; OD: once daily; BID: twice daily.

maximum difference between $\mathrm{OD}$ and dose-equivalent BID regimens was $8 \mathrm{~mL}$ over 24 hours, at steady-state. Differences between the OD and BID regimens for the total daily doses of $25 \mu \mathrm{g}, 50 \mu \mathrm{g}$ and $100 \mu \mathrm{g}$ were small (Table 2). For the $50 \mu \mathrm{g}$ OD dose, the treatment difference over placebo was $123 \mathrm{~mL}\left(62 \% \mathrm{E}_{\max }\right)$ compared with $131 \mathrm{~mL}\left(66 \% \mathrm{E}_{\max }\right)$ for $25 \mu \mathrm{g}$ BID and $98 \mathrm{~mL}(49 \%$ $E_{\max }$ ) for $12.5 \mu \mathrm{g}$ BID.

Dose-response results for $\mathrm{FEV}_{1} \mathrm{AUC}_{0-4 \mathrm{~h}}, \mathrm{FEV}_{1} \mathrm{AUC}_{0-12 \mathrm{~h}}$, and $\mathrm{FEV}_{1} \mathrm{AUC}_{12-24 \mathrm{~h}}$ at steady-state were also comparable for OD and dose-equivalent BID regimens (Table 2). For the $50 \mu \mathrm{g}$ OD dose the treatment difference for $\mathrm{FEV}_{1} \mathrm{AUC}_{0-4 \mathrm{~h}}$ was $165 \mathrm{~mL}\left(79.7 \% \mathrm{E}_{\max }\right)$ versus $153 \mathrm{~mL}\left(73.7 \% \mathrm{E}_{\max }\right)$ for $25 \mu \mathrm{g}$ BID, and $122 \mathrm{~mL}\left(58.9 \% \mathrm{E}_{\max }\right)$ for $12.5 \mu \mathrm{g}$ BID. The treatment difference for $\mathrm{FEV}_{1} \mathrm{AUC}_{0-12 \mathrm{~h}}$ was $152 \mathrm{~mL}$ $\left(73.6 \% \mathrm{E}_{\max }\right)$ for $50 \mu \mathrm{g}$ OD versus $139 \mathrm{~mL}\left(67.1 \% \mathrm{E}_{\max }\right)$ for $25 \mu \mathrm{g}$ BID, and $104 \mathrm{~mL}\left(50.5 \% \mathrm{E}_{\max }\right)$ for $12.5 \mu \mathrm{g}$ BID. Finally, for $\mathrm{FEV}_{1} \mathrm{AUC}_{12-24 \mathrm{~h}}$, the treatment difference was $111 \mathrm{~mL}\left(56.4 \% \mathrm{E}_{\max }\right)$ for $50 \mu \mathrm{g}$ OD compared with $141 \mathrm{~mL}$ (71.4\% $\left.\mathrm{E}_{\max }\right)$ for $25 \mu \mathrm{g}$ BID, and $112 \mathrm{~mL}\left(56.6 \% \mathrm{E}_{\max }\right)$ for $12.5 \mu \mathrm{g}$ BID (Table 2).

\section{Secondary endpoint: peak FEV 1 at Day 28}

When peak $\mathrm{FEV}_{1}$ at steady-state was considered, as anticipated, an advantage was seen for the OD over the BID regimen (Figure 3). For the $50 \mu \mathrm{g}$ OD dose the treatment difference was $168 \mathrm{~mL}\left(82 \% \mathrm{E}_{\max }\right)$, compared with $156 \mathrm{~mL}\left(76 \% \mathrm{E}_{\max }\right)$ for $25 \mu \mathrm{g}$ BID and $126 \mathrm{~mL}$ $\left(61 \% \mathrm{E}_{\max }\right)$ for $12.5 \mu \mathrm{g}$ BID.

\section{Comparison of spirometric profiles}

In general, improvements in spirometric outcomes based on measurements collected $0-12$ hours post-dose $\left(\mathrm{FEV}_{1}\right.$ at $12 \mathrm{~h}, \mathrm{FEV}_{1} \mathrm{AUC}_{0-4 \mathrm{~h}}$ and $\left.\mathrm{FEV}_{1} \mathrm{AUC}_{0-12 \mathrm{~h}}\right)$ were marginally greater for the OD regimens than the BID regimens, whereas the opposite was seen over the period 12-24 hours post-dose. The reason for this can best be visualized through the full spirometry profiles, which are shown for total daily doses of 25,50 and $100 \mu \mathrm{g}$ in Figure 4. The dose response is apparent in these plots, as the profiles are shifted upwards with increasing total daily dose. As can also be seen, the OD profiles were above the BID profiles over the first 12 hours, and below over the last 12 hours. Thus, OD dosing shows more favourable results during the day and BID dosing more favourable results during the night. Over the whole day, those differences tend to cancel out which leaves no meaningful differences between OD and BID dosing in $\mathrm{AUC}_{0-24 \mathrm{~h}}$ (Figure 2).

Figure 4 also shows that the glycopyrronium bromide $50 \mu \mathrm{g}$ OD regimen is the lowest OD dose that provides bronchodilation above or around the minimal clinically important difference (MCID) [12]. Although the $12.5 \mu \mathrm{g}$ BID dose produced a marginally higher improvement in trough $\mathrm{FEV}_{1}$ over placebo than the $50 \mu \mathrm{g}$ OD dose (Day 28), the response it produced in $\mathrm{FEV}_{1}$ at 12 hours after 28 days of treatment over placebo (i.e. $74 \mathrm{~mL}$ ) was below the MCID of $100 \mathrm{~mL}$ (the minimum difference that can be perceived by patients, and which correlates with fewer relapses following exacerbations) [13].

\section{Safety}

The overall incidence of AEs was lower with all glycopyrronium bromide dosages/regimens than with placebo (Table 3). The most commonly reported AEs were: COPD (worsening) in the glycopyrronium bromide 
Table 2 Dose-response relationship for glycopyrronium bromide treatment regimens: model-averaged analysis of trough FEV 1, FEV $_{1}$ AUC $_{0-24 h}, F_{1}$ AUC $_{0-12 h}, F_{1}$ AUC $_{0-4 h}$, and FEV 1 AUC $12-24 \mathrm{~h}$ at steady state

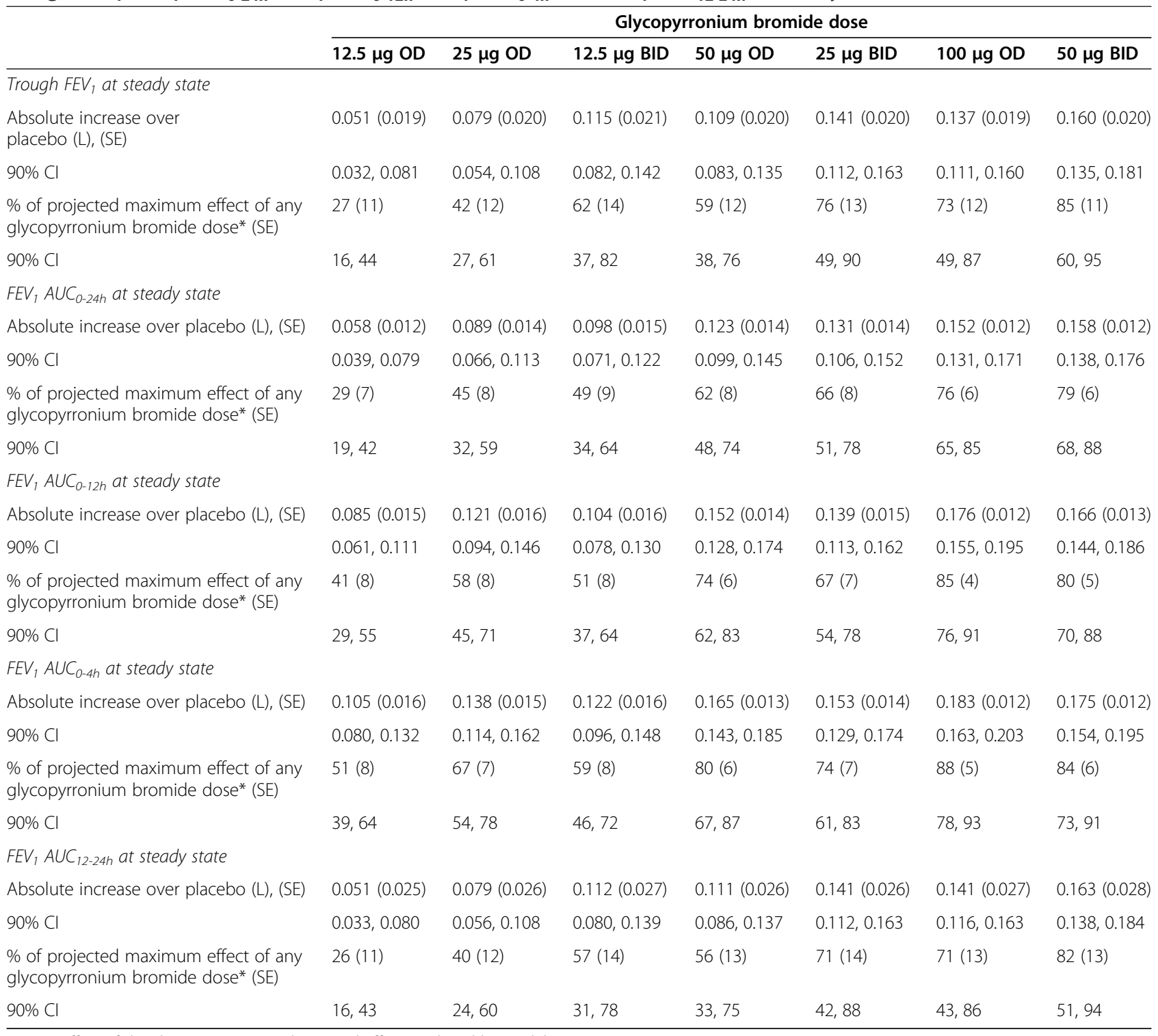

*100 x (effect of this dosage/maximum theoretical effect predicted by model).

OD: once daily; BID: twice daily; SE: standard error; $\mathrm{Cl}$ : confidence interval; $\mathrm{FEV}_{1}$ : forced expiratory volume in one second; AUC: area under the curve.

$12.5 \mu \mathrm{g}$ OD and $25 \mu \mathrm{g}$ BID groups; nasopharyngitis in the glycopyrronium bromide $25 \mu \mathrm{g}$ OD, $50 \mu \mathrm{g}$ OD and $50 \mu \mathrm{g}$ BID groups; both nasopharyngitis and headache in the glycopyrronium bromide $100 \mu \mathrm{g}$ OD and placebo groups; and dyspnoea and diarrhoea in the glycopyrronium bromide $12.5 \mu \mathrm{g}$ BID group. However, differences in $\mathrm{AE}$ frequency between treatments were generally small and there was no difference in severity between the OD and BID regimens.

The proportion of patients with serious AEs was low with all treatments and generally occurred during Period 1. Overall, a total of 21 serious AEs were reported by 19 patients, with COPD worsening being most common (reported by 5 patients). Cardiac disorder was reported in two patients ( 1 patient in the glycopyrronium bromide $50 \mu \mathrm{g}$ BID group had ventricular extrasystoles, 1 patient receiving placebo had angina pectoris). One death was reported during treatment with glycopyrronium bromide $50 \mu \mathrm{g}$ OD during period 2 but was not suspected to be related to study drug.

AEs leading to discontinuation were reported for a small proportion of patients receiving each treatment; 6 patients $(6.7 \%), 3$ patients $(3.1 \%), 1$ patient $(1.1 \%)$, and 3 patients (3.1\%) in the glycopyrronium bromide $12.5 \mu \mathrm{g}$ OD, $25 \mu \mathrm{g}$ OD, $50 \mu \mathrm{g}$ OD, and $100 \mu \mathrm{g}$ OD treatments, and for 1 patient (1.0\%), 5 patients (5.2\%) and 2 patients 


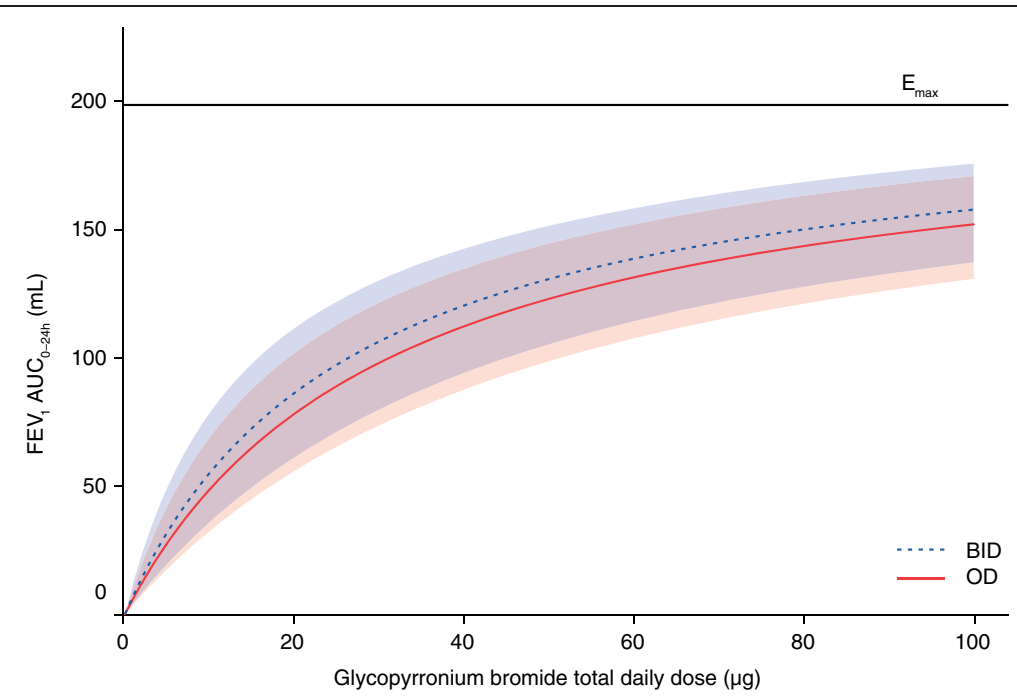

Figure 2 Dose-response results of $\mathrm{FEV}_{1} \mathrm{AUC}_{0-24 \mathrm{~h}}$ at steady-state (modified intent-to-treat population). Model average placebo-adjusted values for OD and BID dosing regimens, with $90 \%$ confidence limits (red and blue shaded areas, respectively). FEV ${ }_{1}$ : forced expiratory volume in one second; AUC: area under the curve; OD: once daily; BID: twice daily.

(2.3\%) receiving glycopyrronium bromide $12.5 \mu \mathrm{g}$ BID, $25 \mu \mathrm{g}$ BID, and $50 \mu \mathrm{g}$ BID, respectively, and 4 patients (4.4\%) receiving placebo. The most common AE leading to discontinuation was COPD worsening. One patient receiving glycopyrronium bromide $50 \mu \mathrm{g}$ BID had a mild headache (on Day 2 of Period 1) that lead to discontinuation and was suspected to be related to study drug.

There were no clinically meaningful changes in haematology or clinical chemistry parameter values during the study, and vital signs showed little effect of glycopyrronium bromide; in all treatment groups, mean minimum and maximum values were in the normal rage for pulse rate (40-90 bpm), diastolic blood pressure (50-90 $\mathrm{mmHg}$ ), and systolic pressure (90-140 $\mathrm{mmHg}$ ). Mean changes from baseline at Day 28 for ECG parameters were small in all treatment groups and not clinically meaningful overall.

\section{Discussion}

Results from this study for trough $\mathrm{FEV}_{1}$ indicate that BID dosing regimens for glycopyrronium bromide produce slightly more bronchodilation compared with OD regimens for an equivalent total daily dose. However, over the course of the 24-hour dosing period, differences

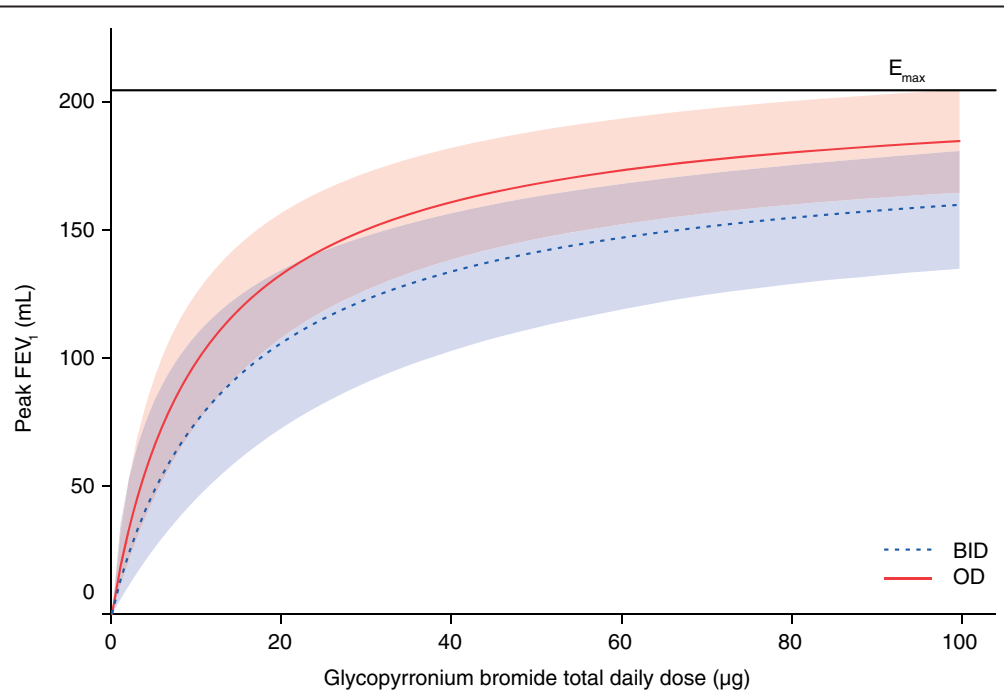

Figure 3 Dose-response results of peak $\mathrm{FEV}_{1}$ at steady-state (modified intent-to-treat population). Model average values for OD and BID dosing regimens, with $90 \%$ confidence limits (red and blue shaded areas, respectively). FEV $\mathrm{F}_{1}$ : forced expiratory volume in one second; OD: once daily; BID: twice daily. 

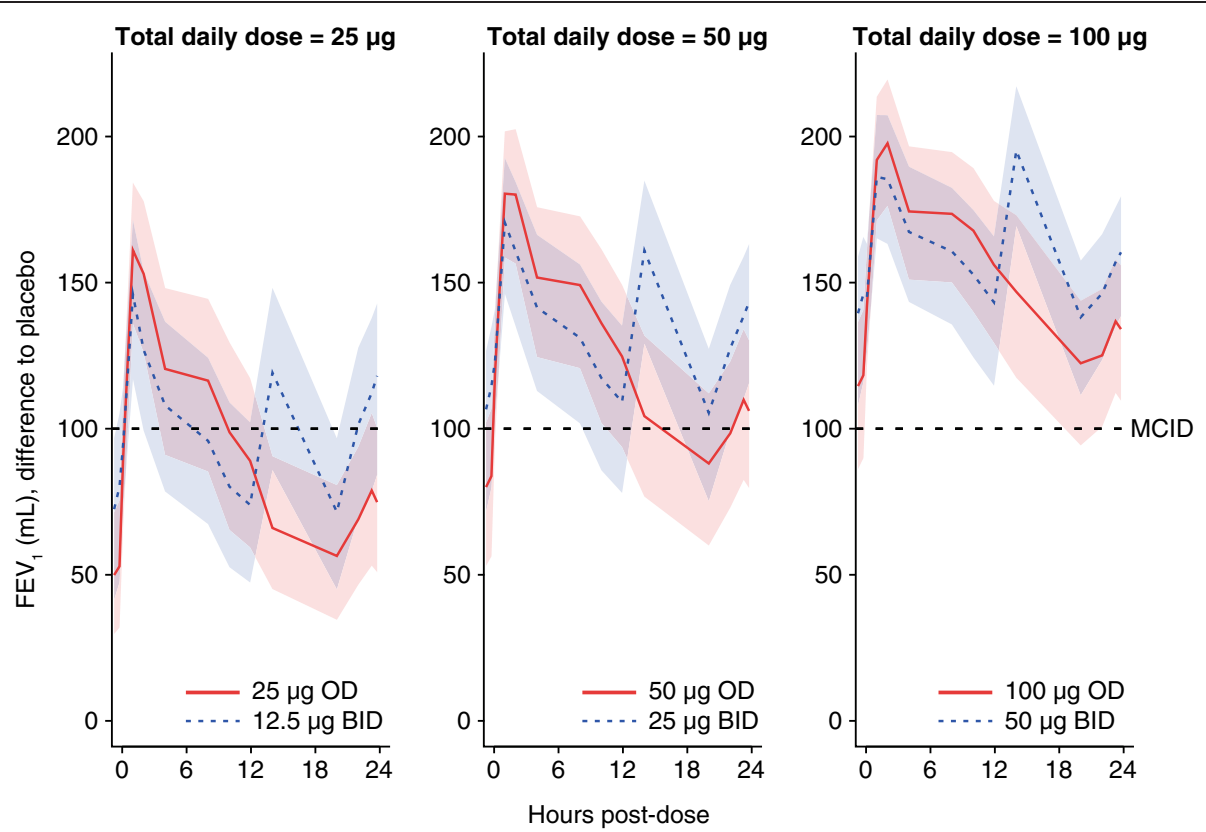

Figure 4 24-hour spirometry results at steady-state (modified intent-to-treat population). Model-based placebo-adjusted values for OD and BID dosing regimens, with 90\% confidence limits (red and blue shaded areas, respectively). MCID $=100 \mathrm{~mL}$ [12]. MCID: minimal clinically important difference; FEV1: forced expiratory volume in one second; OD: once daily; BID: twice daily.

between OD and BID regimens, for an equivalent daily dose, were negligible, and the dose-response relationship for $\mathrm{AUC}_{0-24 \mathrm{~h}} \mathrm{FEV}_{1}$ was driven primarily by total daily dosage.

Dose-response results for $\mathrm{FEV}_{1}$ at 12 hours, $\mathrm{FEV}_{1}$ $\mathrm{AUC}_{0-12 \mathrm{~h}}$ and $\mathrm{FEV}_{1} \mathrm{AUC}_{0-4 \mathrm{~h}}$ at steady-state showed that OD regimens provided greater improvement over placebo than BID regimens for total daily doses of $25 \mu \mathrm{g}$, $50 \mu \mathrm{g}$ and $100 \mu \mathrm{g}$, while the reverse was true for OD versus BID regimens from 12-24 hours (see Table 2). However, over the whole day these differences tend to cancel out, thereby accounting for the lack of meaningful differences between $\mathrm{OD}$ and $\mathrm{BID}$ dosing for $\mathrm{AUC}_{0-}$ 24h. In theory, BID dosing may offer greater improvement in night-time symptoms while OD regimens provide greater improvements in day-time symptoms; the magnitude of the differences in spirometry data between the OD and BID regimens suggests that any symptomatic differences would be also be small.

The $12.5 \mu \mathrm{g}$ BID dose produced a marginally higher improvement in trough $\mathrm{FEV}_{1}$ over placebo than the $50 \mu \mathrm{g}$ OD dose at Day 28, however, the response it produced in $\mathrm{FEV}_{1}$ at 12 hours after 28 days of treatment over placebo $(74 \mathrm{~mL})$ was below the MCID of $100 \mathrm{~mL}$ [13]. These results therefore show that overall $50 \mu \mathrm{g}$ daily is the lowest daily dose of glycopyrronium bromide to provide effective 24-hour bronchodilation. Of interest, similar spirometric profiles were found to those shown in the current study when aclidinium $400 \mu \mathrm{g}$ BID was compared with tiotropium $18 \mu \mathrm{g}$ OD; improvements from baseline in normalized $\mathrm{FEV}_{1}$ were significantly greater for aclidinium vs tiotropium over the last 12 hours on days 1 and 15 [14].

It has been hypothesised that OD dosing may not offer additional benefits over BID dosing in all patients; some symptomatic patients may prefer more frequent relief with a BID regimen [15]. However, simplification of dosing regimens by reducing dosing frequency has been shown to improve adherence with medication $[16,17]$ and has been linked with higher levels of persistence $[4,18,19]$; increased adherence is strongly associated with reduced hospitalization and healthcare utilization costs [20,21]. It has also been suggested that bronchodilators with long durations of action provide a relatively consistent improvement in airway calibre over time, in contrast to the peaks and troughs that can arise with bronchodilators that are dosed twice-daily [22]. Assessment of the dosing regimen(s) likely to provide optimum efficacy should take into account whether adherence is likely to be compromised by increased dosing frequency, and the impact on potential non-adherence on the actual daily dose received. It is also important to remember that adherence tends to be lower in clinical practice than in a clinical trial setting [23-28].

A 24-hour duration of action, combined with a rapid onset of action, are desirable features in a novel LAMA. Phase II and III studies have consistently shown that glycopyrronium bromide $50 \mu \mathrm{g} \mathrm{OD}$ is a suitable dosing 
Table 3 Adverse events occurring during 28 days' treatment with glycopyrronium bromide OD and BID treatment regimens

\begin{tabular}{|c|c|c|c|c|c|c|c|c|}
\hline n (\%) patients & $\begin{array}{l}\text { Glycopyrronium } \\
\text { bromide } 12.5 \mu \mathrm{g} \\
\text { OD }(\mathrm{n}=89)\end{array}$ & $\begin{array}{l}\text { Glycopyrronium } \\
\text { bromide } 25 \mu \mathrm{g} \\
\text { OD }(\mathrm{n}=96)\end{array}$ & $\begin{array}{l}\text { Glycopyrronium } \\
\text { bromide 12.5 } \mu \mathrm{g} \\
\text { BID }(\mathrm{n}=96)\end{array}$ & $\begin{array}{l}\text { Glycopyrronium } \\
\text { bromide } 50 \mu \mathrm{g} \\
\text { OD }(\mathrm{n}=92)\end{array}$ & $\begin{array}{l}\text { Glycopyrronium } \\
\text { bromide } 25 \mu \mathrm{g} \\
\text { BID }(n=96)\end{array}$ & $\begin{array}{l}\text { Glycopyrronium } \\
\text { bromide } 100 \mu \mathrm{g} \\
\text { OD }(\mathrm{n}=96)\end{array}$ & $\begin{array}{l}\text { Glycopyrronium } \\
\text { bromide } 50 \mu \mathrm{g} \\
\text { BID }(\mathrm{n}=87)\end{array}$ & $\begin{array}{l}\text { Placebo } \\
(\mathrm{n}=91)\end{array}$ \\
\hline Any AE & $24(27.0)$ & $20(20.8)$ & $17(17.7)$ & $26(28.3)$ & $23(24.0)$ & $27(28.1)$ & $20(23.0)$ & $29(31.9)$ \\
\hline Any serious $A E$ & $2(2.2)$ & $2(2.1)$ & $1(1.0)$ & $3(3.3)$ & $4(4.2)$ & $3(3.1)$ & $1(1.1)$ & $3(3.3)$ \\
\hline Serious AE leading to discontinuation & $2(2.2)$ & $1(1.0)$ & $1(1.0)$ & $1(1.1)$ & $2(2.1)$ & $2(2.1)$ & 0 & $2(2.2)$ \\
\hline \multicolumn{9}{|l|}{ Most common AEs by preferred term* } \\
\hline Nasopharyngitis & $4(4.5)$ & $8(8.3)$ & $2(2.1)$ & $4(4.3)$ & $3(3.1)$ & $4(4.2)$ & $5(5.7)$ & $6(6.6)$ \\
\hline COPD worsening & $7(7.9)$ & $3(3.1)$ & $2(2.1)$ & 0 & $5(5.2)$ & $3(3.1)$ & $1(1.1)$ & $4(4.4)$ \\
\hline Headache & $1(1.1)$ & $1(1.0)$ & $2(2.1)$ & $3(3.3)$ & $3(3.1)$ & $4(4.2)$ & $3(3.4)$ & $6(6.6)$ \\
\hline Dyspnoea & 0 & $2(2.1)$ & $3(3.1)$ & $3(3.3)$ & $2(2.1)$ & $1(1.0)$ & $4(4.6)$ & 0 \\
\hline Cough & $3(3.4)$ & $3(3.1)$ & $1(1.0)$ & 0 & $1(1.0)$ & $3(3.1)$ & 0 & $2(2.2)$ \\
\hline Diarrhoea & $1(1.1)$ & $2(2.1)$ & $3(3.1)$ & 0 & $1(1.0)$ & 0 & $2(2.3)$ & 0 \\
\hline Dry mouth & 0 & 0 & 0 & $1(1.1)$ & $2(2.1)$ & $2(2.1)$ & $2(2.3)$ & $1(1.1)$ \\
\hline Lower RTI & 0 & 0 & $1(1.0)$ & 0 & $3(3.1)$ & $1(1.0)$ & 0 & 0 \\
\hline
\end{tabular}

$O D$ once daily; $B I D$ twice daily; $A E$ adverse event; $C O P D$ chronic obstructive pulmonary disease; $R T /$ respiratory tract infection. 
regimen providing significant, rapid bronchodilation that is sustained for 24-hours, and clinically meaningful efficacy $[5,6,8,9,29-31]$. Recently published data show that the pharmacokinetics of glycopyrronium bromide $50 \mu \mathrm{g}$ are consistent between doses with limited systemic accumulation at steady-state after repeated once-daily inhalation [32], indicating that glycopyrronium bromide $50 \mu \mathrm{g}$ OD is also a suitable dosing regimen from a pharmacokinetic perspective.

Spirometric measures are important endpoints and the primary means of assessing bronchodilator efficacy in clinical trials; however, symptomatic outcomes may be more meaningful to patients and physicians. Such outcomes should therefore be considered when assessing the relative efficacy of different treatment regimens. It cannot necessarily be assumed that a low-dose regimen that provides equivalent efficacy in increasing $\mathrm{FEV}_{1}$ will also provide equivalent efficacy on symptomatic endpoints. Indeed, a recent systematic review investigating the relationship between $\mathrm{FEV}_{1}$ and other outcomes in COPD found that improvements on the St. George's Respiratory Questionnaire (SGRQ) and Transition Dyspnoea Index correlated with $\mathrm{FEV}_{1}$ in part, but were partly independent of changes in $\mathrm{FEV}_{1}$ [33]. Glycopyrronium bromide $50 \mu \mathrm{g}$ OD has been shown to effectively improve COPD symptoms and reduce exacerbations: in the Phase III GLOW1 study this treatment regimen produced a $108 \mathrm{~mL}$ difference in trough $\mathrm{FEV}_{1}$ (at 12 weeks) compared with placebo $(\mathrm{p}<0.001)$, which is comparable to the difference reported in the present study $(109 \mathrm{~mL}$ versus placebo). In addition, it provided significant improvements in dyspnoea, SGRQ and rescue medication use versus placebo, accompanied by a $31 \%$ decreased risk in moderate/severe exacerbations compared to placebo $(\mathrm{p}=0.023)$ [29].

Glycopyrronium bromide was well tolerated at all doses investigated in this study. The incidence of AEs was similar in glycopyrronium bromide - and placebotreated patients. The results support those from three recently completed Phase III studies (GLOW1, GLOW2 and GLOW3) that show glycopyrronium bromide $50 \mu \mathrm{g}$ OD is well tolerated with a good overall safety profile $[6,29,30]$.

Overall, this study confirmed the efficacy of glycopyrronium bromide $50 \mu \mathrm{g}$ OD, as observed in other studies $[5,8]$, which identified this as an appropriate dosage for further investigation in Phase III trials $[6,29,30]$.

\section{Conclusions}

Differences in terms of $\mathrm{FEV}_{1} \mathrm{AUC}_{0-24 \mathrm{~h}}$ between $\mathrm{OD}$ and the same total daily dose administered BID were small and not clinically relevant. Although both OD and BID dosing appear to be viable, OD dosing is associated with improved patient adherence; an important consideration when selecting the optimum dosing regimen for a novel bronchodilator. Overall, the results of this study support the efficacy and safety data from previous studies and recently completed Phase III trials (GLOW1, GLOW2 and GLOW3), which support glycopyrronium bromide $50 \mu \mathrm{g}$ $\mathrm{OD}$ as a safe, effective and convenient regimen that produces consistent, 24-hour bronchodilation.

\section{Additional files}

Additional file 1: Appendix 1. Study centers and ethics committee. Additional file 2: Appendix 2. Analysis methodology.

\section{Abbreviations}

AE: Adverse event; AUC: Area under the curve; BID: Twice daily; $\mathrm{Cl}$ : Confidence interval; COPD: Chronic obstructive pulmonary disease;

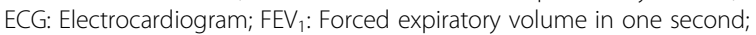
FVC: Forced vital capacity; ICS: Inhaled corticosteroids; LAMA: Long-acting muscarinic antagonist; LABA: Long-acting $\beta_{2}$-agonist; MCID: Minimum clinically important difference; OD: Once daily; SGRQ: St George's Respiratory Questionnaire.

\section{Competing interests}

HA declares no conflict of interest. TO, DR, MG and DB are employees of Novartis Pharma AG.

\section{Authors' contributions}

All authors read and approved the final manuscript.

\section{Acknowledgements}

The study was sponsored by Novartis Pharma AG. The authors were assisted in the preparation of the manuscript by Samantha Stanbury and Melanie Stephens, professional medical writers contracted to CircleScience (Macclesfield, UK), and Mark J. Fedele (Novartis). Writing support was funded by the study sponsor.

\section{Author details}

${ }^{1}$ Medars GmbH, Berlin, Germany. ${ }^{2}$ Novartis Horsham Research Centre, Wimblehurst Road, Horsham, West Sussex RH12 5AB, UK. ${ }^{3}$ Novartis Pharma AG, Basel, Switzerland. ${ }^{4}$ Novartis Pharmaceuticals Corporation, East Hanover, NJ, USA.

Received: 23 July 2012 Accepted: 28 November 2012

Published: 8 December 2012

\section{References}

1. Global initiative for chronic obstructive lung diseases (GOLD): Executive Summary: Global Strategy for the Diagnosis, Management, and Prevention of COPD. (www.goldcopd.com) 2010.

2. World Health Organization (WHO): The global burden of disease 2004 update. Geneva, Switzerland: World Health Organization; 2008.

3. Troosters T, Celli B, Lystig T, Kesten S, Mehra S, Tashkin DP, Decramer M, UPLIFT Study Investigators: Tiotropium as a first maintenance drug in COPD: secondary analysis of the UPLIFT trial. Eur Respir J 2010, 36:65-73.

4. Vogelmeier C, Banerji D: NVA237, a long-acting muscarinic antagonist, as an emerging therapy for chronic obstructive pulmonary disease. Ther Adv Respir Dis 2011, 5:163-173.

5. Verkindre C, Fukuchi Y, Flémale A, Takeda A, Overend T, Prasad N, Dolker M: Sustained 24-h efficacy of NVA237, a once-daily long-acting muscarinic antagonist, in COPD patients. Respir Med 2010, 104:1482-1489.

6. Kerwin E, Hébert J, Gallagher N, Martin C, Overend T, Alagappan VKT, Lu Y, Banerji D: Efficacy and safety of NVA237 versus placebo and tiotropium in patients with moderate-to-severe COPD over 52 weeks: The GLOW2 study. Eur Respir J 2012, 40:1106-14.

7. Overend T, Lu Y, Dolker M, Banerji D: Dose response of NVA237, a longacting muscarinic antagonist for the treatment of COPD. Am J Respir Crit Care Med 2010, 181:A4422. 
8. Fogarty C, Hattersley H, Di Scala L, Drollmann A: Bronchodilatory effects of NVA237, a once daily long-acting muscarinic antagonist, in COPD patients. Respir Med 2010, 105:334-342.

9. Vogelmeier C, Verkindre C, Cheung D, Galdiz JB, Güçlü SZ, Spangenthal S, Overend T, Henley M, Mizutani G, Zeldin RK: Safety and tolerability of NVA237, a once-daily long-acting muscarinic antagonist, in COPD patients. Pulm Pharmacol Ther 2010, 23:438-444.

10. Renard D, Looby M, Kramer B, Lawrence D, Morris D, Stanski DR: Characterization of the bronchodilatory dose response to indacaterol in patients with chronic obstructive pulmonary disease using model-based approaches. Respir Res 2011, 12:54.

11. Renard D, Stanski DR, Morris D, Looby M: Improving dose-response assessments of bronchodilators, using indacaterol as an example. RDD Europe 2011, 1:167-176.

12. Global initiative for chronic obstructive lung diseases (GOLD): Executive Summary: Global Strategy for the Diagnosis, Management, and Prevention of COPD. 2008. www.goldcopd.com.

13. Donohue JF: Minimal clinically important differences in COPD lung function. COPD 2005, 2:111-124.

14. Fuhr R, Magnussen H, Sarem K, Llovera AR, Kirsten A-M, Falques M, Caracta CF, Gil EG: Efficacy of aclidinium bromide $400 \mu \mathrm{g}$ twice daily compared with placebo and tiotropium in patients with moderate to severe COPD. Chest 2012, 141:745-752

15. Agusti A, Vestbo J: Current controversies and future perspectives in chronic obstructive pulmonary disease. Am J Respir Crit Care Med 2011, 184:507-513.

16. Bourbeau J, Bartlett SJ: Patient adherence in COPD. Thorax 2008, 63:831-838.

17. Claxton AJ, Cramer J, Pierce C: A systematic review of the associations between dose regimens and medication compliance. Clin Ther 2001, 23:1296-1310.

18. Breekveldt-Postma NS, Koerselman J, Erkens JA, Lammers JW, Herings RM: Enhanced persistence with tiotropium compared with other respiratory drugs in COPD. Respir Med 2007, 101:1398-1405.

19. Tashkin DP, Fabbri LM: Long-acting beta-agonists in the management of chronic obstructive pulmonary disease: current and future agents. Respir Res 2010, 11:149.

20. Toy EL, Beaulieu NU, McHale JM, Welland TR, Plauschinat CA, Swensen A, Duh MS: Treatment of COPD: relationships between daily dosing frequency, adherence, resource use, and costs. Respir Med 2011, 105:435-441.

21. Calverley PM, Anderson JA, Celli B, Ferguson GT, Jenkins C, Jones PW, Yates $J C$, Yates BS, Vestbo J: Salmeterol and fluticasone propionate and survival in chronic obstructive pulmonary disease. N Engl J Med 2007, 356:775-789.

22. Beeh KM, Beier J: The short, the long and the "ultra-long": why duration of bronchodilator action matters in chronic obstructive pulmonary disease. Adv Ther 2010, 27:150-159.

23. Vestbo J, Anderson JA, Calverley PMA, Celli B, Ferguson GT, Jenkins C, Knobil K, Willits LR, Yates JC, Jones PW: Adherence to inhaled therapy, mortality and hospital admission in COPD. Thorax 2009, 64:939-943.

24. Rand CS, Nides M, Cowles MK, Wise RA, Connett J: Long-term metereddose inhaler adherence in a clinical trial. The Lung Health Study Research Group. Am J Respir Crit Care Med 1995, 152:580-588.

25. van Grunsven PM, van Schayck $C P$, van Deuveren $M$, van Herwaarden $C L$, Akkermans RP, van Weel C: Compliance during long term treatment with fluticasone propionate in subjects with early signs of asthma or chronic obstructive pulmonary disease (COPD): results of the Detection, Intervention, and Monitoring Program of COPD and Asthma (DIMCA) Study. J Asthma 2000, 37:225-234.

26. Haupt D, Krigsman K, Nilsson JL: Medication persistence among patients with asthma/COPD drugs. Pharm World Sci 2008, 30:509-514.

27. Krigsman $K$, Nilsson JL, Ring L: Refill adherence for patients with asthma and COPD: comparison of a pharmacy record database with manually collected repeat prescriptions. Pharmacoepidemiol Drug Saf 2007, 16:441-448

28. Krigsman $\mathrm{K}$, Moen J, Nilsson JL, Ring L: Refill adherence by the elderly for asthma/chronic obstructive pulmonary disease drugs dispensed over a 10-year period. I Clin Pharm Ther 2007, 32:603-611.

29. D'Urzo A, Ferguson G, van Noord JA, Hirata K, Martin C, Horton R, Lu Y, Banerji D, Overend T: Efficacy and safety of once-daily NVA237 in patients with moderate-to-severe COPD: the GLOW1 trial. Respir Res 2011, 12:156.
30. Beeh KM, Singh D, Di Scala L, Drollmann A: Once-daily NVA237 improves exercise tolerance from the first dose in patients with COPD: the GLOW3 trial. Int J COPD 2012, 7:503-513.

31. Korenblat PE, Hebert J, Gallagher N, Martin C, Banerji D, Lu Y: NVA237 once daily improves dyspnea and health-related quality of life in patients with COPD: the GLOW2 trial. Am J Respir Crit Care Med 2012, 185:A2254.

32. Sechaud R, Renard D, Zhang-Auberson L, de la Motte S, Drollmann A, Kaiser G: The pharmacokinetics of multiple inhaled NVA237 doses at four dose levels in COPD patients. Int J Clin Pharmacol Ther 2012, 50:118-128.

33. Westwood M, Bourbeau J, Jones PW, Cerulli A, Capkun-Niggli G, Worthy G: Relationship between $\mathrm{FEV}_{1}$ change and patient-reported outcomes in randomised trials of inhaled bronchodilators for stable COPD: a systematic review. Respir Res 2011, 12:40.

doi:10.1186/1471-2466-12-74

Cite this article as: Arievich et al: A novel model-based approach for dose determination of glycopyrronium bromide in COPD. BMC Pulmonary Medicine 2012 12:74.

\section{Submit your next manuscript to BioMed Central and take full advantage of:}

- Convenient online submission

- Thorough peer review

- No space constraints or color figure charges

- Immediate publication on acceptance

- Inclusion in PubMed, CAS, Scopus and Google Scholar

- Research which is freely available for redistribution

Submit your manuscript at www.biomedcentral.com/submit
C Biomed Central 